\title{
Measurement Uncertainty Evaluation of Digital Modulation Quality Parameters: Magnitude Error and Phase Error
}

\author{
Zhiqiang Zhan ${ }^{1 \mathrm{a}}$, Junwen Xia ${ }^{1}$, Yunling Wang ${ }^{1}$, and Lei Yu ${ }^{1}$ \\ ${ }^{1}$ Division of Electricity and Optics Measurement Technology, Shanghai Institute of Measurement and Testing Technology, China
}

\begin{abstract}
In digital modulation quality parameters traceability, the Error Vector Magnitude, Magnitude Error and Phase Error must be traced, and the measurement uncertainty of the above parameters needs to be assessed. Although the calibration specification JJF1128-2004 Calibration Specification for Vector Signal Analyzers is published domestically, the measurement uncertainty evaluation is unreasonable, the parameters selected is incorrect, and not all error terms are selected in measurement uncertainty evaluation. This article lists formula about magnitude error and phase error, than presents the measurement uncertainty evaluation processes for magnitude error and phase errors.
\end{abstract}

\section{Preface}

Shanghai Institute of Measurement and Testing Technology (SIMT), which is also the National Center of Measurement and Testing for East China, undertakes the task of measurement traceability in East China. When tracing the measurement of digital modulation quality parameters, the most important traceability parameters are Error Vector Magnitude (EVM), magnitude error and phase error. Relevant calibration specifications have been already published, such as JJF1128-2004 Calibration Specification for Vector Signal Analyzers, which specifies the traceability method of EVM, magnitude error and phase error. But in JJF1128-2004 Calibration Specification for Vector Signal Analyzers, the uncertainty assessment methods are not so reasonable, not all the uncertainty components are included, and the assessment method and procedure are also questionable. This article discusses and assesses the source of measurement uncertainty of magnitude error and phase Error, and shows the result of National Comparison of Digital Modulation Quality Parameter organized by China Radio Metrology Technology Committee ([1]). The value of this assessment result is basically same as the result assessed by National Institute of Metrology (NIM).

\section{Measuring method}

According to JJF1128-2004 Calibration Specification for Vector Signal Analyzers, digital modulation quality parameters are calibrated by direct comparison method. Schematic diagram is shown in Figure 1.

Connect calibrated Digital Signal Generator (DSG) to a Vector Signal Analyzer (VSA) or a Spectrum Analyzer with the analyzing function of vector signal. The time base output of Vector Signal Generator (VSG) should be connected to the time base input of VSA, and the time base of VSA should be set as external time base. Set the output frequency of the calibrated DSG, and generally the output level is set to $-10 \mathrm{dBm}$. Select the required standard format or the customized modulation parameters, such as modulation, filter type, filter factor $\alpha$ and symbol rate. Set the input frequency of the VSA equal to the one of calibrated DSG, and input level is -10 $\mathrm{dBm}$ or select Level Auto Range button to regulate the input level of VSA automatically. Select the required modulation standard format or set the modulation system, filter type, filter factor $\alpha$ and symbol rate which is consistent with the VSG. Read the digital modulation quality parameters from VSA.

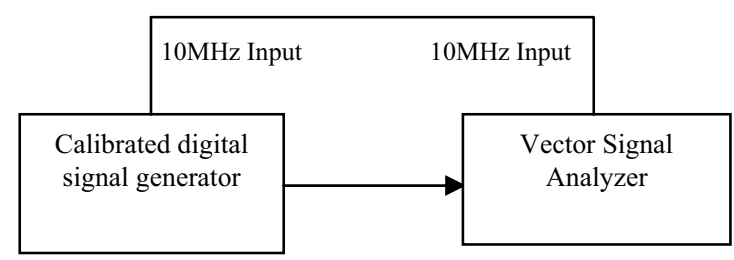

Figure 1. Schematic diagram of digital modulation quality parameter calibration

\section{Definition of digital modulation quality parameter}

For various vector modulation, the signal magnitude and phase can both be represented by the points on the constellation diagram. However, due to the effects such as non-ideal performance of vector modem hardware and the precision of vector modulation algorithm, there are errors occurring between signal vector in real and ideal situation. Vector modulation error defines the error between real constellation points and corresponding

\footnotetext{
${ }^{\mathrm{a}}$ Corresponding author: zhanzq@simt.com.cn
} 
reference constellation points in every symbol period. It is also called Digital Modulation Quality Parameter. The major parameters are magnitude error (MagErr), phase error (PhaseErr) and EVM, shown in Figure 2. Those parameters are usually represented by root mean square (RMS) ([2-3]).

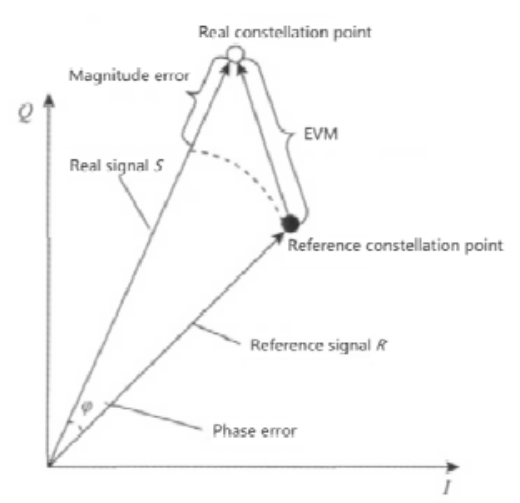

Figure 2. Definition of vector modulation error

As Eq. (1) (3), the subscript rms is expressed as the root mean square value.

$\operatorname{MagErr}_{\text {rms }}$ is expressed as:

$$
\operatorname{MagErr}_{\mathrm{rms}}=\sqrt{\frac{\sum_{i=0}^{i=N-1}\left(\left|S_{i}\right|-\left|R_{i}\right|\right)^{2}}{\sum_{i=0}^{i=N-1}\left|R_{i}\right|^{2}}} \times 100 \%
$$

PhaseErr ${ }_{\mathrm{rms}}$ is expressed as:

$$
\text { PhaseErr } r_{\mathrm{rms}}=\sqrt{\frac{1}{N} \sum_{i=0}^{i=N-1}\left(\arg S_{i}-\arg R_{i}\right)}
$$

$E V M_{\text {rms }}$ is expressed as:

$$
E V M_{\mathrm{rms}}=\sqrt{\frac{\sum_{i=0}^{i=N-1}\left|S_{i}-R_{i}\right|^{2}}{\sum_{i=0}^{i=N-1}\left|R_{i}\right|^{2}}} \times 100 \%
$$

In Eq. (1) (3), $S$ is real signal vector, and $R$ is reference signal vector.

\section{Evaluation of measurement uncertainty of magnitude error}

EVM will be first introduced before the evaluation of measurement uncertainty of digital modulation quality parameters are introduced.

An ideal vector modulation signal expression is shown in the Eq. (4).

$$
V(t)=I(t) \cos \left(2 \pi f_{c} t\right)-Q(t) \sin \left(2 \pi f_{c} t\right)
$$

Assume $I / Q$ gain imbalance degree $g(g=1$ means complete balance), phase error $\varphi$, and interference signal $D \sin \left(2 \pi f_{i} t\right)$ are exist. Phase noise $\theta(t)$ is a random variable which variance is $\sigma_{P} . n(t)$ is Gauss white noise with a variance of $\sigma_{G}$.

Then Eq. (4) turns to Eq. (5):

$$
\begin{aligned}
V(t) & =I(t) \cos \left[2 \pi f_{c} t+\frac{\phi}{2}+\theta(t)\right]-g Q(t) \sin \left[2 \pi f_{c} t-\frac{\phi}{2}+\theta(t)\right] \\
& +n(t)+D \sin \left(2 \pi f_{i} t\right)
\end{aligned}
$$

It is concluded that $E V M$ and the error factor can be obtained by the derivation ([3]).

$$
\begin{gathered}
E V M_{\mathrm{rms}}=\left[2-(1+g) \cos \left(\frac{\varphi}{2}\right) \sqrt{\frac{\frac{\left(g^{2}+g^{2} \sigma_{p}^{2}+\sigma_{p}^{2}+1\right)}{2}}{2}+I S R}\right]^{\frac{1}{2}} \\
I S R=\frac{\sigma_{G}^{2}+\frac{D^{2}}{2}}{I^{2}(t)+Q^{2}(t)}
\end{gathered}
$$

In Eq. (7):

$I / Q$ gain imbalance degree $g$ is a linear value, not a logarithm value.

Unit of phase error $\varphi$ is radian.

$I S R$ is the power ratio of interfering signals and useful signals, and is also a linear value.

If $\varphi=0, E V M$ in Eq. (6) equals MagErr rms.

$$
\operatorname{MagErr}_{\mathrm{rms}}=\left[2-(1+g) \sqrt{\frac{\left(g^{2}+g^{2} \sigma_{p}^{2}+\sigma_{p}^{2}+1\right)}{2}+I S R}\right]^{\frac{1}{2}}
$$

Eq. (8) is the expression of measurement uncertainty of magnitude error in digital modulation quality parameters traceability.

\subsection{Uncertainty source}

In JJF1128-2004 Calibration Specification for Vector Signal Analyzers, an example of measurement uncertainty evaluation is also given. For magnitude error and phase error, its uncertainty source is the error of vector signal generated by the VSG, resolution of VSA and measurement repeatability. When the VSG is to be calibrated, the VSA is the standard. The connection graph is the same as Figure 2, which means calibration of digital modulation quality parameters of VSG and digital modulation quality parameters of VSA is mutual cycle.

From Eq. (8) it can be concluded, when using the DSG to calibrate the digital modulation magnitude error of the VSA, the magnitude error is related to the following factors: $I / Q$ gain imbalance (including inband flatness) $g$, signal-noise ratio $I S R$, phase noise, $I / Q$ origin offset, resolution and measurement repeatability $([2,4,5,6])$.

\subsection{Uncertainty analysis}

The evaluation process of the measurement uncertainty component is introduced below. For the Eq. (8) is complex, in the calculation of the uncertainty of the component, consider the impact of individual components, and finally combine the components.

\subsubsection{Standard measurement uncertainty components produced by I/Q gain imbalance $g$}

$I / Q$ gain imbalance $g$ includes inband flatness, which means $g$ is related to signal bandwidth. Bandwidth of the signal becomes wider, then $I / Q$ gain imbalance increaser, and magnitude error also increaser. 
Only consider the effect of $I / Q$ gain imbalance on magnitude error, it can be obtained from Eq. (8).

$$
\operatorname{MagEr} r_{\mathrm{rms}}=\sqrt{2-(1+g) \sqrt{\frac{2}{1+g^{2}}}}
$$

According to the technical specification, $I / Q$ gain imbalance is 1.01. It can be obtained from Eq. (9).

$$
a_{1}=0.5 \% \text {, }
$$

Assuming it's a uniform distribution, the coverage factor is $\sqrt{3}$.

$$
u_{1}=0.29 \%
$$

\subsubsection{Standard measurement uncertainty components produced by signal-noise ratio}

Signal-noise ratio is the ratio between signal power and noise power. The greater the SNR is, the stronger the receiver's receptivity.

Only consider the effect of $S N R$ on magnitude error, it can be obtained from Eq. (7).

$$
I S R=1 / S N R
$$

Put Eq. (10) into Eq. (8), it can be obtained.

$$
\text { MagErr }_{r m s}=\sqrt{2-2 \sqrt{\frac{1}{1+I S R}}}
$$

In fact, SNR can reach more than $55 \mathrm{~dB}$ in VSA. It can be obtained from Eq. (11).

$$
a_{2}=0.21 \%
$$

Assuming it's a uniform distribution, the coverage factor is $\sqrt{3}$.

$$
u_{2}=0.13 \%
$$

\subsubsection{Standard measurement uncertainty components produced by phase noise}

Phase noise is related to the power spectral density of the single side. With reference to the technical specification, the phase noise parameter of the VSA is roughly as follows:

$$
\begin{gathered}
-80 \mathrm{dBc} / 10 \mathrm{~Hz},-96 \mathrm{dBc} / 100 \mathrm{~Hz},-105 \mathrm{dBc} / 1 \mathrm{kHz}, \\
-127 \mathrm{dBc} / 10 \mathrm{kHz},-126 \mathrm{dBc} / 100 \mathrm{kHz}, \\
-144 \mathrm{dBc} / 1 \mathrm{MHz},-146 \mathrm{dBc} / 10 \mathrm{MHz} .
\end{gathered}
$$

Then:

$\mathrm{N} /(10 \mathrm{~Hz} \sim 100 \mathrm{~Hz})=(-80-96) / 2+10 \lg (100-10)=-68 \mathrm{~dB}$,

Similarly,

$$
\begin{gathered}
\mathrm{N} /(100 \mathrm{~Hz} \sim 1 \mathrm{kHz})=-71 \mathrm{~dB}, \\
\mathrm{~N} /(1 \mathrm{~Hz} \sim 10 \mathrm{kHz})=-76 \mathrm{~dB}, \\
\mathrm{~N} /(10 \mathrm{kHz} \sim 100 \mathrm{kHz})=-77 \mathrm{~dB}, \\
\mathrm{~N} /(100 \mathrm{kHz} \sim 1 \mathrm{MHz})=-75 \mathrm{~dB}, \\
\mathrm{~N} /(1 \mathrm{MHz} \sim 10 \mathrm{MHz})=-75 \mathrm{~dB},
\end{gathered}
$$

Formula of phase jitter is

$$
\text { phase }=\sqrt{10^{\frac{N}{10}} \times 2}
$$

Then:

$$
\begin{aligned}
\text { phase } /(10 \mathrm{~Hz}-100 \mathrm{~Hz}) & =5.6 \times 10^{-4} \\
\text { phase } /(100 \mathrm{~Hz}-1 \mathrm{kHz}) & =4.0 \times 10^{-4} \\
\text { phase } /(1 \mathrm{kHz}-10 \mathrm{kHz}) & =2.2 \times 10^{-4} \\
\text { phase } /(10 \mathrm{kHz}-100 \mathrm{kHz}) & =2.0 \times 10^{-4} \\
\text { phase } /(100 \mathrm{kHz}-1 \mathrm{MHz}) & =2.5 \times 10^{-4}
\end{aligned}
$$

$$
\text { phase } /(1 \mathrm{MHz}-10 \mathrm{MHz})=2.5 \times 10^{-4}
$$

Then:

$$
\begin{gathered}
\sigma_{P}=\text { phase } /(10 \mathrm{~Hz} \sim 10 \mathrm{MHz}) \\
=8.3 \times 10^{-4} \mathrm{rad}
\end{gathered}
$$

Ignoring other factors, it can be obtained by the effect of phase noise on EVM.

$$
\operatorname{MagErr}_{r m s}=\sqrt{2-2 \sqrt{\frac{1}{1+\sigma_{p}^{2}}}}
$$

Put the calculation result of $\sigma_{\mathrm{P}}$ into Eq. (13), then $a_{3}=0.083 \%$. Assuming it's a uniform distribution, the coverage factor is $\sqrt{3}$.

$$
u_{3}=0.05 \%
$$

\subsubsection{Standard measurement uncertainty components produced by $I / Q$ origin offset}

Demodulator imbalance will cause the carrier leakage, which generates an interference signal. It interferences signal vector and deviates it from the correct position, then origin drift. Therefore, origin offset is carrier leakage signal components of demodulated signal.

Ignoring other factors, it can be obtained by the effect of interference signal on magnitude error. It can be obtained from Eq. (8).

$$
\operatorname{MagErr}_{r m s}=\sqrt{2-2 \sqrt{\frac{1}{1+I S R}}}
$$

$I S R$ is $I / Q$ origin offset. According to the technical specification of VSA, $I / Q$ origin offset is $-60 \mathrm{~dB}$. It can be obtained from Eq. (14).

$$
a_{4}=0.1 \%
$$

Assuming it's a uniform distribution, the coverage factor is $\sqrt{3}$.

$$
u_{4}=0.06 \%
$$

\subsubsection{Standard measurement uncertainty components produced by resolution}

When the vector signal is demodulated by the VSA, the minimum resolution is 0.01 .

$$
a_{5}=0.005 \%
$$

Assuming it's a uniform distribution, the coverage factor is $\sqrt{3}$.

$$
u_{5}=0.003 \%
$$

\subsubsection{Standard measurement uncertainty components produced by measurement repeatability}

Measure the magnitude error for 10 times when standard value is $4.5 \%$.

\begin{tabular}{|c|c|}
\hline Times & Measurement Value \\
\hline 1 & $4.51 \%$ \\
\hline 2 & $4.48 \%$ \\
\hline 3 & $4.51 \%$ \\
\hline 4 & $4.49 \%$ \\
\hline 5 & $4.48 \%$ \\
\hline 6 & $4.49 \%$ \\
\hline 7 & $4.52 \%$ \\
\hline
\end{tabular}




\begin{tabular}{|c|c|}
\hline 8 & $4.52 \%$ \\
\hline 9 & $4.52 \%$ \\
\hline 10 & $4.49 \%$ \\
\hline
\end{tabular}

According to the Bessel formula:

$$
u_{6}=S=0.013 \%
$$

\subsection{Calculation of the combined standard uncertainty}

\subsubsection{List of uncertainty}

\begin{tabular}{|c|c|c|c|c|c|c|}
\hline \multirow[b]{2}{*}{ No. } & \multicolumn{6}{|c|}{ The uncertainty component } \\
\hline & $\begin{array}{l}\text { The sources } \\
\text { of the } \\
\text { uncertainty }\end{array}$ & Type & $\begin{array}{c}\text { Symbol } \\
\text { and } \\
\text { value }\end{array}$ & Distribution & $\begin{array}{c}\text { The } \\
\text { coverage } \\
\text { factor }\end{array}$ & $\begin{array}{l}\text { The symbol } \\
\text { and value } \\
\text { of standard } \\
\text { uncertainty }\end{array}$ \\
\hline 1 & $\begin{array}{l}I / Q \text { gain } \\
\text { imbalance }\end{array}$ & B & $a_{1}=0.5 \%$ & Uniform & $\sqrt{3}$ & $u_{1}=0.29 \%$ \\
\hline 2 & $\begin{array}{l}\text { signal-noise } \\
\text { ratio }\end{array}$ & B & $\begin{array}{c}a_{2}=0.22 \\
\%\end{array}$ & Uniform & $\sqrt{3}$ & $u_{2}=0.13 \%$ \\
\hline 3 & phase noise & B & $\begin{array}{c}a_{3}=0.08 \\
\%\end{array}$ & Uniform & $\sqrt{3}$ & $u_{3}=0.05 \%$ \\
\hline 4 & $\begin{array}{l}I / Q \text { origin } \\
\text { offset }\end{array}$ & B & $a_{4}=0.1 \%$ & Uniform & $\sqrt{3}$ & $u_{4}=0.06 \%$ \\
\hline 5 & resolution & B & $\begin{array}{c}a_{4}=0.005 \\
\%\end{array}$ & Uniform & $\sqrt{3}$ & $u_{5}=0.003 \%$ \\
\hline 6 & $\begin{array}{l}\text { measurement } \\
\text { repeatability }\end{array}$ & A & 1 & I & I & $u_{6}=0.013 \%$ \\
\hline
\end{tabular}

\subsubsection{The synthesis of the standard uncertainty}

Each Standard uncertainty component is independent from each other with no correlation, then consider the larger value of resolution and measurement repeatability involved in the synthesis of the standard uncertainty.

$$
u=\sqrt{u_{1}^{2}+u_{2}^{2}+u_{3}^{2}+u_{4}^{2}+u_{6}^{2}}=0.328 \%
$$

\subsection{The expanded uncertainty}

The coverage factor is 2 .

$$
U=0.66 \%(k=2)
$$

\section{Evaluation of measurement uncertainty of phase error}

\subsection{Uncertainty source}

Phase error is related to the following factors: $I / Q$ gain imbalance, $I / Q$ origin offset, resolution and measurement repeatability.

\subsection{Uncertainty analysis}

\subsubsection{Standard measurement uncertainty components produced by $I / Q$ gain imbalance}

The formula of the effect of $I / Q$ gain imbalance on phase error is:

$$
\text { PhaseErr }=45-\frac{180}{\pi} \operatorname{arctg}\left(\frac{1}{g}\right)
$$

According to the previous hypothesis, $g=1.01$. Error is $1 \%$.

$$
a_{1}=0.29^{\circ}
$$

Assuming it's a uniform distribution, the coverage factor is $\sqrt{3}$.

$$
u_{1}=0.17^{\circ}
$$

\subsubsection{Standard measurement uncertainty components produced by $I / Q$ origin offset}

Figure 3 as an example, the effect of $I / Q$ origin offset on the measurement results is introduced. According to the analysis, the magnitude of the error vector is perpendicular to $\mathrm{X}$ axis, and the $I / Q$ origin is shifted in $\mathrm{X}$ axis, which has the greatest influence on the phase error.

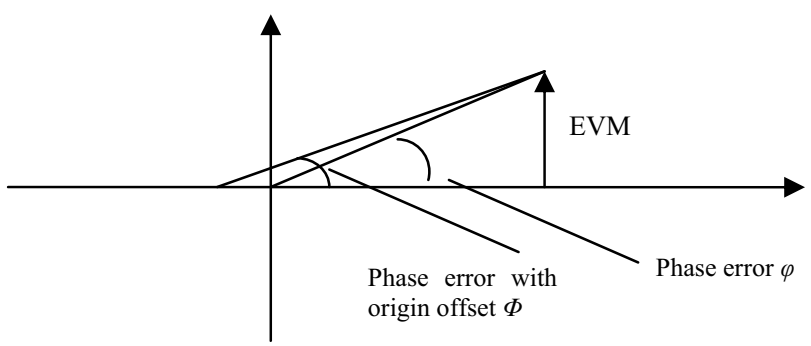

Figure 3. Phase error with origin offset

Assuming the origin offset is $-60 \mathrm{~dB}$, which is $0.1 \%$. According to Figure 3, the influence of the phase error is approximately equal to the origin offset value, which is in radian. It needs to multiply $\frac{180^{\circ}}{\pi}$, then turns to degree. $a_{2}=0.06^{\circ}$

Assuming it's a uniform distribution, the coverage factor is $\sqrt{3}$.

$$
u_{2}=0.04^{\circ}
$$

\subsubsection{Standard measurement uncertainty components produced by resolution}

Resolution is $0.01^{\circ}$.

$$
a_{3}=0.005^{\circ} \text {, }
$$

Assuming it's a uniform distribution, the coverage factor is $\sqrt{3}$.

$$
u_{3}=0.003^{\circ}
$$

\subsubsection{Standard measurement uncertainty components produced by measurement repeatability}

Measure 10 times.

\begin{tabular}{|c|c|}
\hline Times & Measurement Value \\
\hline 1 & $3.49^{\circ}$ \\
\hline 2 & $3.50^{\circ}$ \\
\hline 3 & $3.48^{\circ}$ \\
\hline 4 & $3.49^{\circ}$ \\
\hline 5 & $3.50^{\circ}$ \\
\hline 6 & $3.49^{\circ}$ \\
\hline
\end{tabular}




\begin{tabular}{|c|c|}
\hline 7 & $3.50^{\circ}$ \\
\hline 8 & $3.51^{\circ}$ \\
\hline 9 & $3.51^{\circ}$ \\
\hline 10 & $3.51^{\circ}$ \\
\hline
\end{tabular}

Then

$$
u_{4}=\mathrm{s}=0.010^{\circ}
$$

\subsection{Calculation of the combined standard uncertainty}

\subsubsection{List of uncertainty}

\begin{tabular}{|c|c|c|c|c|c|c|}
\hline No. & \multicolumn{6}{|c|}{ The uncertainty component } \\
\cline { 2 - 7 } the uncertainty & Type & $\begin{array}{c}\text { Symbol } \\
\text { and } \\
\text { value }\end{array}$ & Distribution & $\begin{array}{c}\text { The } \\
\text { coverage } \\
\text { factor }\end{array}$ & $\begin{array}{c}\text { The symbol and } \\
\text { value of } \\
\text { standard } \\
\text { uncertainty }\end{array}$ \\
\hline 1 & $\begin{array}{c}I / Q \text { gain } \\
\text { imbalance }\end{array}$ & $\mathrm{B}$ & $a_{1}=0.29^{\circ}$ & Uniform & $\sqrt{3}$ & $u_{1}=0.17^{\circ}$ \\
\hline 2 & $\begin{array}{c}I / Q \text { origin } \\
\text { offset }\end{array}$ & $\mathrm{B}$ & $a_{2}=0.06^{\circ}$ & Uniform & $\sqrt{3}$ & $u_{2}=0.033^{\circ}$ \\
\hline 3 & $\begin{array}{c}\text { resolution } \\
\text { measurement } \\
\text { repeatability }\end{array}$ & $\mathrm{B}$ & $a_{3}=0.005$ & Uniform & $\sqrt{3}$ & $u_{3}=0.003^{\circ}$ \\
\hline 4 & $/$ & $/$ & $/$ & $u_{4}=0.010^{\circ}$ \\
\hline
\end{tabular}

\subsubsection{The synthesis of the standard uncertainty}

Each Standard uncertainty component is independent from each other with no correlation, then consider the larger value of resolution and measurement repeatability involved in the synthesis of the standard uncertainty.

$$
u=\sqrt{u_{1}^{2}+u_{2}^{2}+u_{4}^{2}}=0.174^{\circ}
$$

\subsection{The expanded uncertainty}

The coverage factor is 2 .

$$
U=0.35^{\circ}(k=2)
$$

\section{Conclusion}

In JJF1128-2004 Calibration Specification for Vector Signal Analyzers, the measurement uncertainty evaluation of magnitude error is unreasonable and the measurement uncertainty evaluation formula of phase error is not perfect. In this article, the uncertainty source of the magnitude error and phase error are comprehensively analyzed. In line with the principle of non repetition and no missing, measurement uncertainty of magnitude error and phase error are assessed. This article is uncertainty evaluation content when participating in the National Comparison of Digital Modulation Quality Parameters organized by China Radio Metrology Technology Committee. Table 1 and Table 2 are part of the result of National Comparison of Digital Modulation Quality Parameters.

Table 1. Magnitude error comparison result $(1800 \mathrm{MHz}$,

\begin{tabular}{|c|c|c|}
\hline Company & $\begin{array}{l}\text { Measurement } \\
\text { value }\end{array}$ & $\begin{array}{c}\text { Uncertainty } \\
\quad(k=2)\end{array}$ \\
\hline $\begin{array}{c}\text { National Institute of } \\
\text { Metrology,China(Comparison leading } \\
\text { laboratory) }\end{array}$ & $4.49 \%$ & $0.61 \%$ \\
\hline $\begin{array}{c}\text { Ministry of Industry and Information } \\
\text { Technology Communication } \\
\text { Measurement Center } \\
\end{array}$ & $4.5 \%$ & $1.1 \%$ \\
\hline $\begin{array}{c}\text { China Aerospace Science\&Industry } \\
\text { Corporation } 203 \\
\end{array}$ & $4.51 \%$ & $0.45 \%$ \\
\hline $\begin{array}{l}\text { Measurement and testing center of } \\
\text { research laboratory equipment of } \\
\text { General Armament Department }\end{array}$ & $4.5 \%$ & $1.0 \%$ \\
\hline Keysight Technologies,Inc. & $4.52 \%$ & $0.82 \%$ \\
\hline $\begin{array}{l}\text { Rodhe\&Schwarz(China)Technology } \\
\text { Co.,Ltd }\end{array}$ & $4.5 \%$ & $1.0 \%$ \\
\hline $\begin{array}{c}\text { Beijing Oriental Institute of } \\
\text { Measurement and Test }\end{array}$ & $4.5 \%$ & $1.0 \%$ \\
\hline National Instruments Corporation & $4.55 \%$ & $0.70 \%$ \\
\hline $\begin{array}{c}\text { Shanghai Institute of Measurement and } \\
\text { Testing Technology }\end{array}$ & $4.51 \%$ & $0.66 \%$ \\
\hline Jiangsu Institute of Metrology & $4.5 \%$ & $1.0 \%$ \\
\hline $\begin{array}{c}\text { Guangdong Provincial Institute of } \\
\text { Metrology }\end{array}$ & $4.54 \%$ & $0.62 \%$ \\
\hline $\begin{array}{c}\text { The Fifth Electronics Research } \\
\text { Institute of Ministry of Industry and } \\
\text { Information Technology }\end{array}$ & $4.47 \%$ & $0.08 \%$ \\
\hline
\end{tabular}
16QAM modulation, symbol rate $4 \mathrm{Mbit} / \mathrm{s}$, filter $\mathrm{RRC}$, filter coefficient 0.22 )
Table 2. Phase error comparison result (1800MHz, 16QAM

\begin{tabular}{|c|c|c|}
\hline Company & $\begin{array}{l}\text { Measurement } \\
\text { value }\end{array}$ & $\begin{array}{l}\text { Uncertainty } \\
\qquad(k=2)\end{array}$ \\
\hline $\begin{array}{c}\text { National Institute of } \\
\text { Metrology,China(Comparison leading } \\
\text { laboratory) }\end{array}$ & $3.50^{\circ}$ & $0.28^{\circ}$ \\
\hline $\begin{array}{c}\text { Ministry of Industry and Information } \\
\text { Technology Communication } \\
\text { Measurement Center }\end{array}$ & $3.51^{\circ}$ & $0.61^{\circ}$ \\
\hline $\begin{array}{c}\text { China Aerospace Science\&Industry } \\
\text { Corporation } 203\end{array}$ & $3.51^{\circ}$ & $0.28^{\circ}$ \\
\hline $\begin{array}{l}\text { Measurement and testing center of } \\
\text { research laboratory equipment of } \\
\text { General Armament Department }\end{array}$ & $3.50^{\circ}$ & $0.62^{\circ}$ \\
\hline Keysight Technologies,Inc. & $3.52^{\circ}$ & $0.57^{\circ}$ \\
\hline $\begin{array}{c}\text { Rodhe\&Schwarz(China)Technology } \\
\text { Co.,Ltd }\end{array}$ & $3.50^{\circ}$ & $0.62^{\circ}$ \\
\hline $\begin{array}{c}\text { Beijing Oriental Institute of } \\
\text { Measurement and Test }\end{array}$ & $3.5^{\circ}$ & $0.5^{\circ}$ \\
\hline National Instruments Corporation & $3.52^{\circ}$ & $0.20^{\circ}$ \\
\hline $\begin{array}{c}\text { Shanghai Institute of Measurement } \\
\text { and Testing Technology }\end{array}$ & $3.50^{\circ}$ & $0.35^{\circ}$ \\
\hline Jiangsu Institute of Metrology & $3.5^{\circ}$ & $0.6^{\circ}$ \\
\hline $\begin{array}{c}\text { Guangdong Provincial Institute of } \\
\text { Metrology }\end{array}$ & $3.53^{\circ}$ & $0.72^{\circ}$ \\
\hline $\begin{array}{c}\text { The Fifth Electronics Research } \\
\text { Institute of Ministry of Industry and } \\
\text { Information Technology }\end{array}$ & $3.48^{\circ}$ & $0.28^{\circ}$ \\
\hline
\end{tabular}
modulation, symbol rate $4 \mathrm{Mbit} / \mathrm{s}$, filter RRC, filter coefficient $0.22)$

From table 1 and table 2, the evaluation of measurement uncertainty is basically same as the result assessed by Comparison leading laboratory (NIM). 


\section{Acknowledgements}

The author wishes to thank Key Laboratory of Shanghai On-line measurement and control technology and all colleagues who provided technical support.

This work was supported by the National Science \& Technology Pillar Program (Grant No. 2014BAK02B04), the Project of General Administration of Quality Supervision, Inspection and Quarantine of the People's Republic of China (Grant No.2014QK138).

\section{References}

1. Fang Hong, Bian Xin ,He Zhao,Zhou Xin, Research on Measurement Method of Vector Modulation Error based on Constellation Diagram, Chinese Journal of Scientific Instrument, Vol.34 No.1 Jan. (2013) pp128 132

2. Fang Hong, Bian Xin ,Zhou Xin, Liu Ke, The Numerical Simulation and Experiment Research for Measurement of Error Vector Magnitude(EVM), Applied Mechanics and Materials, Vol.103(2012) pp199-204
3. Zhang Rui, Zhou Feng,Guo Long Qing, Wireless Communication Instrument and Test Application, Posts\&Telecom Press, pp135 138.2011

4. Cheng Yi Xin, Measurement and Testing Technology for the Uncertainty Analysis of Error Vector Magnitude, Vol 37 No.12(2010) pp62 68

5. Wu You Zhang, Zhao Hai Ning, Yu Hui Dong, Calibration and Measurement of Digital Modulation Quality Parameters, Acta Metrologica Sinica, 2005, 26( 3) : pp271 274

6. Khald M. Gharaibeh, Kevin G. and Michael B. Steer. Accurate Estimation of Digital Communication System Metria-SNR, EVM and $\mathrm{p}$ in a Nonlinear Amplifier Environment. ARFTG Microwave Measurements Conference, Fall 2004. 64th, 2 3 Dec. 2004:41 44.

7. The people's Republic of China National Metrology Technical specification, JJF 1128-2004 Calibration Specification for Vector Signal Analyzers, China Metrology Publishing House, 2004

8. The people's Republic of China National Metrology Technical specification, JJF 1174-2007 Calibration Specification for Digital Signal Generator, China Metrology Publishing House, 2007 